\title{
FRICTION MECHANISM OF POLYMERS AND THEIR COMPOSITES
}

\author{
Gordana Bogoeva-Gaceva ${ }^{1,2}$, Dimko Dimeski ${ }^{3}$, Vineta Srebrenkoska ${ }^{3}$ \\ ${ }^{1}$ Faculty of Technology and Metallurgy, Ss. Cyril and Methodius University, \\ Rudjer Bošković 16, 1000 Skopje, Republic of Macedonia \\ ${ }^{2}$ Research Center for Environment and Materials, Macedonian Academy of Sciences and Arts, \\ Blvd. Krste Misirkov 2, 1000 Skopje, Republic of Macedonia \\ ${ }^{3}$ Faculty of Technology, Goce Delčev University, Krste Misirkov 102 A \\ 2000 Štip, Republic of Macedonia \\ gordana@tmf.ukim.edu.mk
}

This paper provides a brief review of the tribological properties of polymers and polymer matrix composites (PMCs) and the relevant mechanisms of friction and wear. The influence of both molecular and mechanical components on friction involving polymers as well as the influence of fillers, reinforcements and dry lubricants on the overall tribological characteristics of PMCs is evaluated. Tribological parameters include surface roughness, the mechanism of adhesion, friction and wear, and chemical interactions with dry lubricants (if present). The article reviews the main factors that influence the wear and frictional characteristics of thermoplastic and thermosetting polymers, short fiber reinforced composites and high-performance unidirectional composites. Examples of quantitative data of different pairs of polymers and PMCs with the counterface are presented.

Keywords: polymer composites; tribology; friction and wear

\section{МЕХАНИЗАМ НА ТРИЕЊЕ КАЈ ПОЛИМЕРИТЕ И ПОЛИМЕРНИТЕ КОМПОЗИТИ}

Во трудот е даден краток преглед на триболошките својства на полимерите и композитите со полимерна матрица, како и на механизмите на триење и абење. Дискутирано е влијанието на молекуларната и механичката компонента при триењето на полимерите, како и влијанието на полнилата, зајакнувачките компоненти и мазивата на вкупните триболошки карактеристики на полимерните композити. Триболошките параметри вклучуваат површинска рапавост, механизам на атхезија, триење и абење и хемиски интеракции со сувите мазива, доколку се присутни. Во трудот се елаборирани основните фактори кои влијаат на абењето и триењето кај термопластичните и термореактивните полимери, кај композитите зајакнати со кратки влакна и кај еднонасочните високоперформансни композити. Прикажани се примери на квантитативни податоци за различни парови полимери и композити при триење со различни површини.

Клучни зборови: полимерни композити; трибологија; триење и абење

\section{INTRODUCTION}

The interactions at the interface between two surfaces of bodies in relative motion cause friction and wear of the materials involved. These interactions lead to the transmission of forces and the dissipation of mass (wear) and energy (friction); the related phenomena are the subject of the science of tribology [1]. Friction and wear are not intrinsic material properties but depend on experimental parameters and conditions of use. Also, various material properties (physical, chemical, mechanical and adhesive) are responsible for differences in wear behavior [2]. However, no direct correlation 
exists between wear and mechanical properties such as the tensile and flexural strength, elongation, hardness or impact resistance of a material [3].

The reinforcement of polymers, both thermoplastics and thermosets, with fibers/fillers reduces the extent of interaction of the polymer with the counterface and increases the load-carrying capacity and strength of the obtained composite material. Polymer composite materials offer wide possibilities of tailor-making a desired combination of a variety of properties, such as high specific strength, high fatigue resistance, resistance against surface corrosion, self-lubrication, and, in general, good price-performance ratio. Polymer composites have replaced metals in many load-bearing applications because of their lightweight and good mechanical performance. They are often used as structural components that are often subjected to friction and wear loadings under use. Depending on the particular application, the kind of wear loading can be very different, and therefore the selection of the material (both the polymer matrix and reinforcement) and the structure of the composite material used to fulfill the particular requirements of certain application can also be very different [4].

In certain situations, the coefficient of friction is of the highest importance, but largely it is the wear life of components and the mechanical load-carrying capacity that determines the acceptability of PMCs in industrial applications [5]. In various tribological applications, the composite material must be able to support the dynamic stresses induced by the applied load and the tangential friction forces. Various kinds of wear (e.g. adhesive, abrasive, fatigue, fretting fatigue, erosive and corrosive), alone or in combination, can occur, depending on the operating parameters and overall properties of the PMC [6]. It should be mentioned that the overall properties of PMCs, including their tribological behavior, greatly depend not only on the type of fiber used, but also on the shape of the reinforcing component and the degree of anisotropy. A schematic representation of sphere-, fiberand ribbon-reinforced composite systems possessing one-, two- or three-dimensional anisotropy of the mechanical properties is shown in Fig. 1.

More complicated structural composition exists, for example in laminated, knitted or woven textile fabrics or unidirectionally oriented continuous fiber plies aligned in different directions to produce the required property profile in the final material [5]. Commonly used fibers in polymer composites, such as glass, carbon, graphite and aramid, are all available as short, long or fabric reinforcement for both thermoset and thermoplastic polymers. Besides the type of reinforcement, fiber orientation relative to the sliding plane greatly affects the wear of composites in sliding wear mode. Due to the unique properties profile, PMCs reinforced with both short and unidirectionally oriented long fibers have recently become the most important classes of triboengineering materials [7].

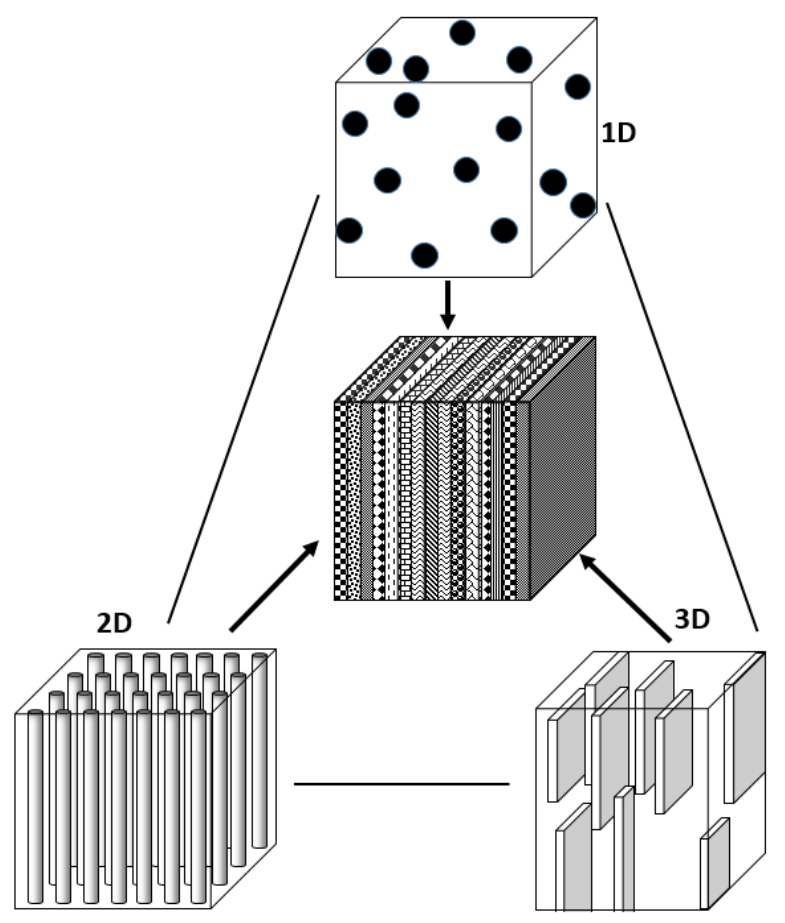

Fig. 1. Schematic representation of different composite structures having a different degree of anisotropy

\section{COEFFICIENT OF FRICTION}

Friction represents resistance to the relative tangential displacement of two bodies that are in a contact under the action of normal and tangential forces. There are three important factors affecting friction: deformation, affecting the real area of contact of surfaces (i.e. the area of contact between asperities of the bodies, touching the other before the load is applied, which is much smaller than the geometrical area of the bodies) (see Fig. 2a) (i), adhesion of surfaces in contact (ii) and shear resulting in film transfer and debris formation (iii) [8]. The deformation component results from the resistance of the polymer (which forms the surface of the PCM) to "ploughing" by the asperities of the harder counterface when a load is applied (see Fig. 2b).

The adhesion component stems from the adhesive junctions formed at spots of real contact between the surfaces, and for polymers is believed to exceed deformation by far. 

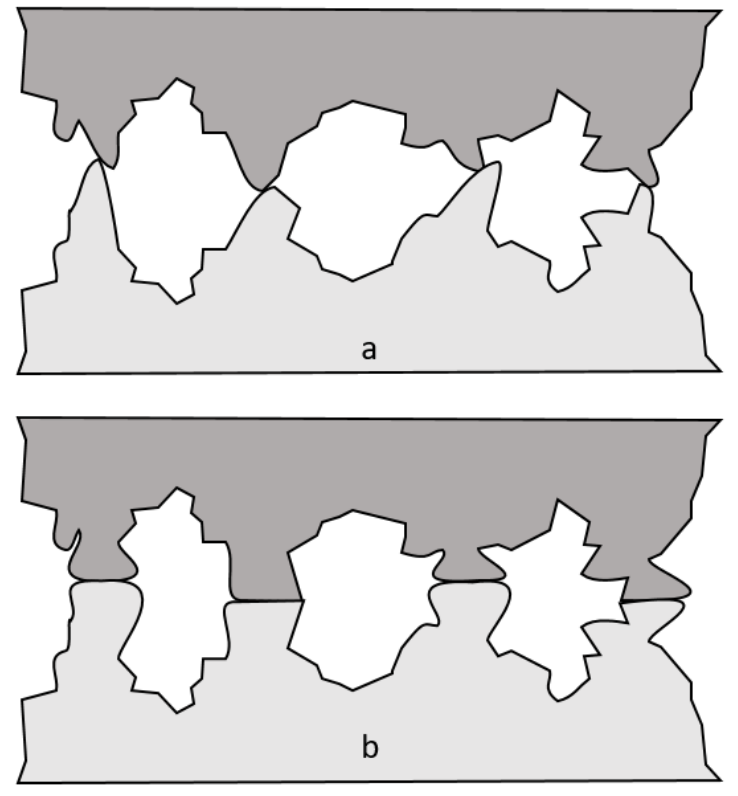

Fig. 2. The top image (a) shows asperities under no load. The bottom image (b) depicts the same surface after applying a load.

Considering the practical aspect, the destruction of the surface layer is an especially important characteristic of polymeric materials. The formation of a transferred polymer film during friction is a key factor determining the tribological behavior of polymers and PMCs [9]. It should be taken into consideration that friction appears only in certain parts of the contact surface, i.e. at socalled friction contacts (i.e. contacts between asperities), due to the roughness of the polymer material surface. Quantitative indicators of this process are [5]:

- sliding (also known as kinematic or dynamic) coefficient of friction $\mu=F / N(F-$ friction force, $N$-normal force: $\mathrm{N}=\mathrm{mg}$ ),

- rolling coefficient of friction, $\kappa=F R / N(R-$ radius of the rolling body)

- static coefficient of friction, $\Psi=F_{l} / N\left(F_{1}-\right.$ incomplete force of friction to induce motion of the body, $F_{l}<F$ ).

Contrary to the sliding and static coefficients, which are dimensionless, the rolling coefficient has units of length $(\mathrm{mm})$.

Generally, the force of friction, $F$, depends on the normal force, $N$, the surface roughness, the sliding speed $v$, the temperature and the duration of contact.

\section{MOLECULAR-MECHANICAL THEORY}

The dependence of friction on the normal force, roughness and type of surfaces in contact is successfully described by the molecular-mechanical theory [5], developed by Kragelsky [10] and Boden and Tabor [11]. According to this theory, the total surface of the friction contacts constitutes the real contact surface, $S_{\mathrm{r}}$, which is always smaller than the nominal surface, $S_{\mathrm{n}}$, determined by the geometrical dimensions of the two contact surfaces. Therefore, the real pressure on the bodies is defined as:

$$
P_{\mathrm{r}}=N / S_{\mathrm{r}}
$$

and nominal pressure:

$$
P_{\mathrm{n}}=N / S_{\mathrm{a}}
$$

The work of the friction force consists mainly of the molecular component, which is consumed to exceed inter-molecular interactions and leads to the formation of "friction junctions" (10) or "seizure (cold welding) bridges" (11) in the friction contacts, and of the mechanical component, which is consumed by deforming the surface roughness of the bodies that rub. A considerably less work is consumed on electro-charging, on the accumulation of elastic energy in the deformed volume and on other accompanying processes. According to molecular-mechanical theory, the friction force can be represented as the sum of two terms:

$$
F=F_{\text {mol }}+F_{\text {mech }}
$$

where $F_{\text {mol }}$ and $F_{\text {mech }}$ are the molecular and mechanical components of the friction force, respectively. After dividing both parts of this relationship by the normal load, we obtain:

$$
\mu=\mu_{\text {mol }}+\mu_{\text {mech }}
$$

where $\mu, \mu_{\text {mol and }} \mu_{\text {mech }}$ are the complete coefficient of friction and its molecular and mechanical components, respectively.

It is supposed that, in the case of sliding, the resistance to shearing down in the contact zone should be smaller than that in the deep layers, i.e. there is a gradient of shear resistance. Therefore, for polymer-polymer friction, polymers should be chosen for which thermal mechanical or thermooxidative destruction will take place during friction; as a result, a layer will be formed on the surface with low resistance to shearing. In the case of a polymer-metal pair, during destruction, lowmolecular weight compounds are formed, which may lead to adsorptive reduction of metal roughness. Moreover, during friction, these compounds can polymerize to form metal-containing polymers.

From the viewpoint of mechanics, an elementary friction junction is a combination of two 
processes, one of which is the deformation of the surface volume of the materials involved and the second is the process of shear surface destruction of the adhesion junction [10]. During friction, the surface layer may be considered a "third body" (friction body). If it is supposed that in it, the molecular mobility is sufficiently high, then the molecular component of the friction coefficient during sliding, $\mu_{m o l}$, can be characterized by the shear resistance coefficient, $\tau$. The increase in shear resistance with an increase in pressure will be:

$$
\tau=\tau_{0}+\beta P_{\mathrm{r}}
$$

where:

$\tau_{0}-$ value of $\tau$ during $P_{\mathrm{r}}=0$,

$\beta$-so-called piezo coefficient of the friction molecular component.

The constants $\tau_{0}$ and $\beta$ are determined experimentally for many metal-polymer pairs. For example, in a pair with steel, $\tau_{0}$ changes from $0.35 \mathrm{MNm}^{-2}$ for fluoroplasts to $1.5 \mathrm{MNm}^{-2}$ for polyamide, and $\beta$ from 0.02 to 0.04 , respectively. Hence, for a steelteflon (polytetrafluorethylene, PTFE) pair, $\tau=0.35$ $\times 0.02=0.07 \mathrm{MNm}^{-2}$ and for a steel-polyamide pair (PA6), $\tau=1.5 \times 0.04=0.06 \mathrm{MNm}^{-2}$.

The deformation (mechanical) component of the friction coefficient, $\mu_{d e f}$, is determined by the expression:

$$
\mu_{d e f}=\alpha \cdot C \sqrt{\frac{h}{r}}
$$

where:

$\alpha-\mathrm{a}$ constant that expresses the hysteresis energy losses during multiple elastic deformations of the roughness,

$C$ - coefficient determined by the surface profile,

$h$ - maximal depth of a single rough part (depth of penetration of the sphere into the material),

$r$ - radius of curvature (radius of a spherical rigid body, "punch", considered to be a model of a single asperity).

By experimental measurements, it has been established that the deformation component of the friction coefficient for thermoplastic polymers and for tires is considerably higher than the same in thermosetting resins, for which it usually has a lower value. In that way, the total coefficient of friction, determined by equations 3 (in which both parts are divided by $P_{\mathrm{r}}$ ) and 4 , is represented by the following equation [5]:

$$
\mu=\frac{\tau_{0}}{P_{r}}+\beta+\alpha \cdot C \sqrt{\frac{h}{r}}
$$

This is the basic equation of the molecularmechanical theory, in which the first two members denote the molecular component of the coefficient of friction. According to this expression, the dependence of the friction coefficient on the load and the degree of roughness represents a mathematical function characterized by a minimum. This allows for an explanation of the essence of "gain" during friction: the degree of roughness changes in a way that, for a given loading, the value of the coefficient reaches its minimum.

The molecular-mechanical friction theory enables a determination of the friction coefficient dependence from the nature of a body and its external condition, but only for stationary regimes, i.e. under conditions with reproducibility of the formed non-surface layers with small shear resistance. Besides this, in this theory, the rheological properties of the polymers are not taken into consideration.

The dependence of friction on the sliding speed and temperature is included in the theory, according to which friction is determined by the thermo-fluctuation processes of formation and destruction of the molecular bonds in the zone of frictional contact. The bonds break due to the thermal effect (frictional heating), the energy of which is characterized by $k \mathrm{~T}$ ( $k$ is the Boltzmann constant). The role of pulling, i.e. the resistance force (equal and reverse in the direction of $F$ ) is only in the reduction of the activation energy of the process, $U$.

For a polymer in a viscoelastic state, the sliding speed is:

$$
v=B \cdot e^{-\frac{U-\gamma \cdot F}{k T}}
$$

where $B$ and $\gamma$ are constants.

This formula serves well in cases of small normal forces, $N$ and large friction forces, $F$.

In accordance with the molecular-kinetic theory, a polymer sliding along a smooth surface of a tougher counter-body is realized through the thermal leap of polymer segments from one position to another during fretting. The sliding speed, $v$, is connected to the time of relaxation of polymer chains, $\theta$,

$$
v=\frac{\lambda}{\theta} I_{1}\left(\frac{\gamma F}{k T}\right) \approx \frac{\lambda}{\theta} \sqrt{\frac{k T}{2 \pi \gamma F}} e^{-\frac{U-\gamma F}{k T}}
$$


where

$\lambda$ - average distance between adjacent equilibrium positions on the chain,

$I_{1}$ - modified Bessel function of the first degree.

By implementing the principle of temperature-time superposition, it is possible to determine the relation between the sliding speed and the temperature, and the functions $F(v)$ and $F(T)$, in a broad interval of speeds and temperatures.

The duration of static contact has an influence on the friction strength in the steady state, $F s$, called the stop effect. The dependence of the friction force on time, $t$, in the steady state, is given as:

$$
F s=F_{\infty}-\left(F_{\infty}-F_{0}\right) e^{-n \cdot t}
$$

where:

$n$ - a constant that characterizes the rheological properties of the polymer and the degree of roughness of the surface contact,

$F_{0}$ - friction force at time $t=0$,

$F_{\infty}$ - friction force at time $t=\infty$.

\subsection{Tribological behavior of polymers}

The tribological behavior of polymers is different from those of metals and ceramic materials. Polymers have a very low surface free energy and viscoelastic properties, which leads to drastic tribological differences when the adhesive and mechanical components of friction force are considered [12]. Their advantage over other materials is the possibility of various modifications to their surface and bulk properties, especially reinforcement with fillers and/or fibers (used in different forms).

In order to determine the optimum material combination with respect to a low coefficient of friction and high wear resistance, different combinations of polymers and fibers have been widely investigated $[3,5-7,9,13]$. Thus, the use of polymers and PMCs is typical in tribological applications, including thermoplastics and thermosets such as polytetraflorethylene (PTFE), polyamides (mostly PA6 and PA6.6), ultra-high molecular weight polyethylene (UHMW-PE), polyetheretherketone (PEEK), polyphenylene sulfide (PPS), polyacetals, polyimides, polyurethanes, epoxides and phenolic resins. The most frequently used reinforcing fibers are carbon, aramid, glass and cotton (applied as short or long fibers, or in the form of a fabric). In general, the incorporation of organic (polytetraflorethylene) and carbon fibers in polymers drastically increases their wear re- sistance, i.e. by approximately $3.8 \times$ for $\mathrm{PVC}$, by $3 \times$ for PTFE, by $2.5 \times$ for PP and by $1.2 \times$ for PA. It should also be mentioned that carbon fiberreinforced composites exhibit stable values of the coefficient of friction, practically independently of the number of friction cycles, with $N$ in the range of $(2-15) \times 10^{4}[14]$. The addition of fillers/fibers in thermoplastics, in some cases, has been found to reduce the heat generated in the interface by reducing the interaction between the asperities at which the transferred film will not adhere well and detachments may occur. Another possible influence of the presence of fibers is the strong film transfer made of polymer and fiber debris on the countersurface [15].

Polyamides represent a major class of tribopolymers used in various types of friction and wear situations, due to their wear and abrasive resistance and advanced mechanical properties. Systematic flat on flat wear experiments performed with several types of polyamides in reciprocating sliding contact with steel under a normal load of $9000 \mathrm{~N}$ and sliding speed of $10 \mathrm{mms}^{-1}$ revealed that the tribological properties are affected by the chemical composition, mechanical properties of the polymers and the service temperature. It was shown that PA6.6 sliding against steel is sensitive to stickslip motion; favorable friction and wear behavior was observed in $\mathrm{MoS}_{2}$-filled PA6.6 $(\mu=0.15-$ $0.20)$ [16]. Glass and carbon fiber reinforcement greatly improve the friction and wear performance of polyamide 11 and polyamide 12 [17]. Polytetrafluorethylene (PETF) is a well-known low-friction thermoplastic with excellent chemical and thermal stability, often used in tribological applications. Interestingly, to improve the tribological properties of PETF, besides the incorporation of fiber reinforcements, as-received nanodiamond (known for its excellent tribological properties) was recently introduced into the PETF matrix. A reduced friction coefficient and wear at $23{ }^{\circ} \mathrm{C}$ and $150{ }^{\circ} \mathrm{C}$ were observed and ascribed not only to the low friction coefficient of nanodiamond, but also to a change in the microstructure of the nanocomposites, observed by SEM [18]. In general, nanoparticle fillers have been key to notable reductions in the wear rate of polymer matrices at very low loadings (even at $0.5 \%$ ), yet there is still a lack of general agreement in the literature on the mechanism of wear resistance in nanocomposites $[18,19]$. The friction and wear characteristics of PMCs can be improved either by reducing their adhesion to the counterface or by enhancing their mechanical properties. PETF is often used not only as a matrix, but also as an in- 
ternal lubricant incorporated in other polymeric matrices, so that during sliding, the PETF film is transferred to the counterface to reduce the friction coefficient [20].

Epoxy resins are usually combined with glass, carbon and other fibers to produce hard and strong composite materials. They have been long recognized as promising tribological materials [21]. The effect of the counterpart material, internal lubricant (PTFE, graphite, $\mathrm{MoS}_{2}$ and $\mathrm{SnS}_{2}$ ) and fiber reinforcement (glass and carbon fibers) on the wear of epoxy-based composites has been investigated [22]. Additionally, the friction mechanism of sliding between epoxy resins and stainless steel has been investigated. It was found that, in the glassy region, the value of the friction coefficient was constant in spite of variations in contact pressure [23]. A trace of shearing fracture was observed on the sliding surfaces, and a linear relationship existed between the friction coefficient and the shear modulus of the cured resin.

The coefficient of friction of polyurethanes (PU) on steel depends on their grade (it drops as the hardness increases) and is usually approximately 0.2. The slip speed has a small effect on the coefficient of friction, as higher slip speeds lead to a slightly higher coefficient of friction. The application of higher load increases the frictional force, although there is a tendency for the coefficient of friction to fall over time. This effect is most probably due to lubrication of the interface by abrasion debris. An increasing tendency in the coefficient of friction (up to 0.45 ) with load has been shown for smooth molded plastic surfaces [24, 25].

Phenolic resins are well known for their excellent heat resistance and durability and are widely used as resins for friction materials. Additional valuable properties, such as high abrasion resistance, improved formability, fast curability and/or flexibility, can be obtained by their modification with different elastomers, epoxides, rubber, etc. [14].

As mentioned above, the tribological behavior of a material is, in general, characterized by two main parameters: the coefficient of friction (static, $\mu_{\mathrm{s}}$ and dynamic, $\mu_{\mathrm{d}}$ ) and the wear behavior under certain conditions. The friction data obtained for different polymers and polymer-counterface pairs are usually explained on the basis of the above presented molecular-mechanical model, according to which the coefficient of friction $(\mu)$ represents the sum of the piezo coefficient of the molecular part of friction, a deformational part $\left(\mu_{\mathrm{def}}\right)$ controlled by the surface profile and asperities and their elastic deformation, and a mechanical part representing the shear-resistance of frictional con- tact under increasing load [5, 14, 25]. In general, it is known that, for thermoplastics and rubbers, $\mu_{\text {def }}$ is much higher than for thermosetting polymers. Also, thermoplastic polymers have the ability to undergo thin film transfer onto the metal counterface, which can assist in reducing the overall frictional coefficient. The wear rate of thermoplastics is reduced by their reinforcement. The possibility of generating film transfer on the counterface in thermosetting polymers is less pronounced, but the film is harder and can sustain high temperatures. The addition of abrasive fibers to thermosets could enhance their wear and friction properties.

In general, it should be mentioned that friction in actual applications is very difficult to predict because of the wide range of surface combinations, the non-linear relationship between the contact pressure, the sliding speed and the coefficient of friction $\left(\mu_{\mathrm{d}}\right)$, and because of the effect of increasing temperature due to frictional heating on the coefficient of friction. For polymers, this can be even more complicated because polymers do not always follow the applicable classical laws of friction, because of the large plastic deformations that occur at the tips of asperities. Polymers do not react in this way, and the larger range of elastic deformation means that the coefficient of friction is generally lower than for other materials under the same conditions. It is therefore only possible to give indicative values for the coefficient of friction for polymers, unless the specific application conditions are stated. Most polymers have average coefficients of friction in the range 0.2 to 0.6 [26]. The parameters that dictate the tribological performance of polymers also include the polymer molecular structure, morphology, processing and treatment, viscoelastic behavior, surface texture, etc. [27]. Clearly, polymers with higher temperature resistance are more tolerant to heat that develops in the contact area during the sliding process. This represents a route toward improving the wear performance of the material [28].

\subsection{Tribological behavior of composites}

The coefficient of friction of fiber-reinforced polymer composite materials, among other factors, greatly depends on the fiber orientation. For instance, values for $\mu$ from $0.30-0.60$ were found in carbon fiber-reinforced composites with different fiber orientations. The lowest values of the coefficient of friction were determined for the composites in which the reinforcing fibers were oriented in the direction of the friction force. 
The developments in tribological research on advanced PMCs are presented in numerous review articles [6, 7, 12, 13, 15, 21, 29, 30].

\subsection{Short fiber-reinforced composites}

The short fibers (with loading of approximately $20-30 \%$ ) usually yield a reduction in wear rate when incorporated into a thermoplastic polymer matrix. In short fiber-reinforced thermoplastics, there is a quasi-random fiber distribution across the plaque thickness. The most frequently used fibers are carbon, glass and aramid. Glass fibers are effective in reducing wear but generally affect $\mu$ adversely, while carbon and graphite fibers are effective in reducing both, apart from enhancing thermal conductivity. Aramid fibers (effective in reducing both friction and wear) are often the most favored fibers in tribo-composites [30, 31]. Short carbon fibers have been found to be better in this respect than the more abrasive glass fibers, although a little abrasiveness can be considered beneficial with respect to smoothing the roughness of the counterface. This is why high strength carbon fibers with higher abrasiveness, but the same lubricating efficiency as high modulus graphite fibers, are preferred for high performance composites in sliding wear applications [32]. Investigations into the tribological behavior of short carbon fiber reinforced polyetherimide (PEI) have shown that the addition of 5-20 vol.\% fibers results in significantly improved wear resistance, especially at elevated temperatures [33].

Analysis of the specific wear rates as a function of the fiber (glass, carbon) volume fraction for wide variety of different short fiber-reinforced thermoplastics (PPS, PES, PA 6.6, PET, PETF or thermotropic liquid crystalline polymer (LCP)), measured under the same testing conditions, has shown that, regardless of the material, the specific wear rates are between $5 \times 10^{-7}$ and $8 \times 10^{-6}$ $\mathrm{mm}^{3} \mathrm{~N}^{-1} \mathrm{~m}^{-1}$ [25]. Carbon fibers demonstrate superiority over glass fibers in an LCP matrix at about the same volume content. The optimum fiber loading seems to be between 20 and 30 vol\%. Above this level, slight increases in the wear rate were observed for several short fiber-filled polymer systems [30].

The process of material removal is dominated by four different mechanisms: matrix wear (abrasion), fiber sliding wear, fiber cracking and wear by fiber-matrix separation (debonding, fiber pull-out) at the interface. It has been found in different studies that surface treatment of the fibers plays an important role in increasing adhesion between the fiber and the matrix, thus reducing the chance of debonding occurrence. An effective route to further improving the performance of the material is the use of polymer matrices with higher temperature resistance, preferably filled with some degree of internal lubricant (graphite, PTFE, $\mathrm{MoS}_{2}$, $\mathrm{SiO}_{2}, \mathrm{SiC}$, etc.) [5].

The tribological behavior of PTFE composites containing a combination of carbon or glass fibers, and the addition of graphite $(7 \%), \mathrm{MoS}_{2}$ $(5 \%)$ and poly-p-phenylene terephthalamide $(10 \%)$ (as a high-temperature fiber) revealed that the presence of fillers increased the hardness and wear resistance in all composites studied, and that composites with higher heat absorption capacity exhibited improved wear resistance [34]. The lubricant reduced via $\mu$ the temperature generated in the contact area, and the high temperature polymer itself was more tolerant to temperatures that develop in the contact area during the sliding process. Among these polymers, differently lubricated thermosetting polyimide (PI) formulations (i.e., $15 \%$ graphite and $10 \%$ fluorocarbon resin fillers) and short fiber-filled polyetheretherketone (PEEK) were considered especially promising candidates [35]. In order to find the optimum material combination with respect to a low coefficient of friction and high wear resistance, high performance polymers with superior mechanical properties, high thermal resistance and better wear stability (PEEK, or polyamide imide, PAI) have been blended with a low friction material (PTFE) in different volume fractions [36, 37]. Among the short fiber-reinforced thermoplastics assessed for sliding wear applications were POM (polyoxymethylene)/PTFE fiber and PA 6.6/aramid fiber composites [38]. In general, polyacetals are strong, stiff and have good impact resistance, a low coefficient of friction and good abrasion resistance. The steady-state wear rate of POM/PTFE composites has been found to be influenced by both the surface topography of the steel counterface and by the characteristic of the transfer layer formed after running in.

It has been shown that short fibers used in PEEK or PTFE matrices yield a reduction in the wear rate of the composite. Short carbon fibers are better in this respect than more abrasive glass fibers, although a little abrasiveness, as already mentioned, can be considered beneficial with respect to smoothing the roughness of the counterface [6]. The wear mechanism developed for short fiberreinforced composites includes matrix wear, fiber sliding wear, fiber cracking and wear by fibermatrix separation at the interface [39]. The last two processes occur sequentially and can be considered 
as a combined process. The removal of fibers also causes an additional matrix wear process, because the fiber particles can act as third-body abrasives.

\subsection{High-performance UD polymer composites}

The composites in this group consist of continuous fibers with a high volume fraction and perfect alignment. It is understandable that these composites in unidirectional form exhibit a much more pronounced dependence of their friction and wear properties in the sliding direction than the very short fiber-reinforced composites.

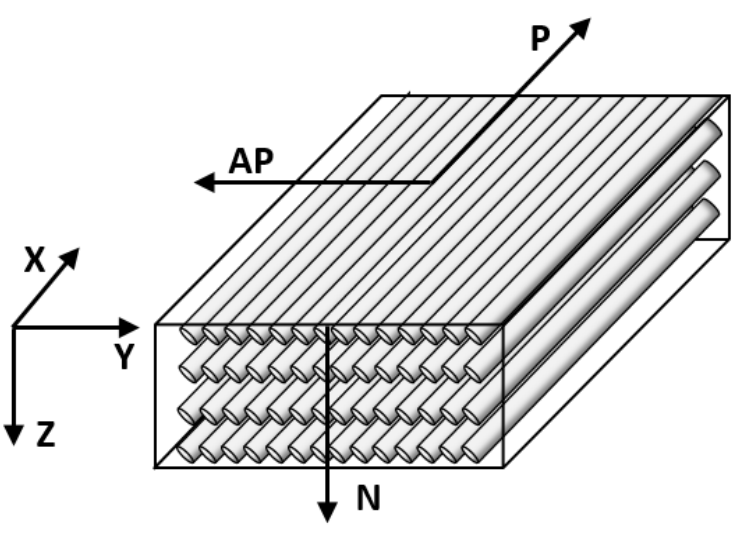

Fig. 3. Basic wear directions for UD-composites: $\mathrm{P}$ - parallel, $\mathrm{N}$ - normal, AP - antiparallel

It is often observed that sliding on a plane with a normal fiber orientation results in lower wear rates than those which are measured for the two other extreme possibilities - in-plane sliding parallel or antiparallel to the fiber orientation [40]. The opposite trend is frequently observed for the coefficient of friction. The effect of the fiber type is the same as that reported for short-fiber composites: carbon fibers (CF) are superior to glass fibers (GF), and aramid fibers (AF) are similar to CF [6, 41]. The friction coefficient can be increased or decreased, depending on the sliding pairs and operating parameters (normal load, sliding velocity, amplitude and frequency of vibration, duration of the contact, etc.). There are also some correlations between friction/wear and other influencing parameters, and can be used to design different tribological and mechanical components [29].

For a mathematical description of the wear rates of UD-composites, the same model that was initially developed for short glass-fiber composites, described by the following equation, can be applied [39]:

$$
\begin{aligned}
W_{s, c}^{\&}= & {\left[\left(1-V_{f}\right)\left(W_{s, m}^{\&}\right)^{-1}+0.5\left(1+V_{f}^{c}\right) \cdot V_{f}\left(W_{s, F_{s}}^{\&}\right)^{-1}\right]^{-1} } \\
+ & 0.5\left(1-V_{f}^{c}\right) \cdot V_{f}\left(W_{s, f_{c i}}^{\&}\right) \\
& W_{s, c}^{\&}-\text { the composite wear rate, } \\
& W_{s, m}-\text { the matrix wear rate, } \\
& W_{s, f}-\text { the fiber sliding wear rate. } \\
& \text { To calculate the coefficient of friction is }
\end{aligned}
$$
somewhat easier, because this property follows a simple rule of mixed approach. This has been shown by Tzukizoe for unidirectional glass-, carbon- and aramid fiber-reinforced epoxy matrix composites [5]:

$$
\mu_{c}^{-1}=\left(1-\frac{A_{f}}{A_{o}}\right) \mu_{m}^{-1}+\frac{A_{f}}{A_{o}} \mu_{f}^{-1}
$$

where:

$A_{f}$ - is the exposed area of fiber,

$A_{o}$ - is the total sliding surface area,

$c, m, f-$ are indices for the composite, polymer matrix and fiber, respectively.

For certain applications, hybrid composites are produced using two different types of fibers. Such hybrid composites, based on brittle epoxy resin or a tough thermoplastic PEEK, in which a reasonable content of carbon fibers is replaced by glass fibers, have been investigated with respect to their wear resistance [42]. Also, synergistic effects are seen for the wear resistance of 2D hybrid composites with aramid fibers in a normal orientation and carbon fibers in a parallel orientation [43].

3D hybrid composites with high wear resistance in the parallel sliding direction have been made of woven fabric with carbon (AP and P orientations) and aramid fibers ( $\mathrm{N}$ orientation) in a PEEK matrix [30]. The synergistic effects were attributed to fiber interlocking in the contact area as a result of the woven structure of the reinforcement [44]. A polymer composite with high resistance against severe abrasion should have PEEK as the matrix and aramid fibers in a normal orientation to the contact area. A composite with overall good wear resistance could be made by threedimensional hybridization, with interwoven carbon fibers in plane ( $x y$ plane) and aramid fibers in the $z$ direction, in a high wear resistance polymer (such as PEEK) [25]. Excellent wear resistance even at high temperatures $\left(\sim 310^{\circ} \mathrm{C}\right)$ has been determined for composites with a 3D fiber arrangement (carbon fibers, CF, glass fibers, GF) and a high temperature polymer matrix (PI) with lubricants as inclusions [45]. A slight improvement, even by several orders of magnitude, in sliding wear re- 
sistance of an epoxy matrix composite reinforced with glass, carbon and aramid fibers (used as woven fabrics or UD-arrangements) has been reported [46].

For PPS/carbon fiber composites, analysis of the effect of fiber orientation with respect to the sliding direction has shown that the friction coefficient was in the order $\mu_{\mathrm{AP}}<\mu_{\mathrm{P}}<\mu_{\mathrm{N}}$ (AP - antiparallel, $\mathrm{P}$ - parallel, $\mathrm{N}$ - normal). The same wear studies against abrasive paper have shown that the value of the specific wear rate was in order of fiber orientation as $\mathrm{N}<\mathrm{AP}<\mathrm{P}$, regardless of variations in speed or load [47].

It is known that friction and wear at the micro- and nanolevels occur on very smooth contact areas comparable to a given system size and, therefore, the role of adhesion and surface forces becomes negligible [48, 49]. Miniaturization of the friction contact models needs a transfer from the volume properties of the materials to their surface features [48]. In general, micro- and nanotribology requires new principal approaches [50-52].

The authors have taken a part in a European research project investigating the substitution of metallic pistons with composites in advanced hydraulic and pneumatic valves. The primary requirement for the composite was good friction resistance. Other requirements involved good strength, fatigue resistance, dimensional stability, low weight and the ability to serve as a substrate for thin metallic coatings. Our research involved many composites based on thermosetting/thermoplastic matrices reinforced with glass, carbon, aramid and UHMWPE (ultra-high molecular weight polyethylene) fibers and selection of the most suitable candidate for the purpose. As in many other applications, our investigation has shown that composites can successfully substitute metals in specific tribo-applications $[53,54]$.

\section{CONCLUSION}

Traditional tribology, developed originally for metals, cannot be fully applied to PMCs for at least two reasons. First, PMCs are viscoelastic materials and their properties depend on time and temperature - contrary to metals and ceramics. Second, certain external liquid lubricants, which work well for other classes of materials, are easily absorbed by PMCs, causing swelling and dimensional instability. The friction mechanism of polymers and PMCs is a complex process that includes adhesion, mechanical deformation and chemical bonding of the rubbing bodies as well as film and debris formation. The friction data for the main representatives of thermoplastic and thermosetting polymers are discussed on the basis of the molecular-mechanical theory of friction. The inclusion of fillers/fibers in both thermosetting and thermoplastic polymers can increase their strength and hardness, which can result in significant improvements in friction resistance. Due to the anisotropic nature of PMCs, their relative orientation to the counterface can also significantly influence the tribological properties of the friction pairs. An important advantage of PMCs is their ability to be custom-made to best match the counterface, thus producing favorable synergy in tribological applications. Thermoplastic-based composites have been observed to be more suitable in a wide range of applications than brittle thermoset composites. This is mainly due to their ability to form a soft thin film on the counterface, as compared to thermosets, which assists in reducing the friction coefficient without forming a film. For highperformance UD composites, carbon fibers in the parallel orientation and aramid fibers in the normal orientation have been observed to result in enhanced wear performance of the composites. Synergistic effects have been seen in hybrid composites where two types of reinforcing fibers are combined in a woven fabric reinforcement.

\section{REFERENCES}

[1] E. Rabinowitcz, Friction and Wear of Materials, Wiley, New York, 1965.

[2] H. Czichos, Tribology, A Systems Approach to the Science and Technology of Friction, Lubrication and Wear, Tribology Series, vol. 1, Elsevier, Amsterdam, 1978.

[3] N. Chand, M. Fahrim, Introduction to tribology of polymer composites. In: Tribology of Natural Fiber Polymer Composites, Woodhead Publ. in Composite Sci. \& Technol., 2008, pp. 59-83.

[4] M. Cirino, The friction and wear behavior of unidirectional continuous fiber reinforced polymer composites, M.S. Thesis, Center for Composite Materials, University of Delaware, 1985.

[5] International Encyclopedia of Composites, vol. 4, Stuart M. Lee (Ed.), VCH, New York, 1989, pp. 256-272.

[6] H. H. Parigh, P. P. Gohil, Tribology of fiber reinforced polymer matrix composites - A review, J. Reinf. Plastics Composites, 2015.

DOI: 10.1177/0731684415591199, jrp.sagepub.com.

[7] P. Gohil Piyush, H. Parikh Hiral, Composites as TRIBO materials in engineering systems: significance and applicatios. In: Advances in Chemical and Materials Engineering (ACME) Book Series: Processing Techniques and Tribological Behavior of Composite Materials. USA: IGI Publisher, 2015, pp. 168-191. 
[8] N. Myshkin, A. Kovalev. In: Polymer Tribology, S. Sinha, B. Briscoe (Eds); Imperial College London, 2009, Chapter 1, pp. 3-37.

[9] N. Myshkin, A. Kovalev, D. Spaltman, M. Woydt, Contact mechanics and tribology of polymer composites, $J$. Appl. Polym. Sci. 2014. DOI: 10.1002/APP.39870.

[10] I. V. Kragelsky, V. P. Sabelnikov, Experimental check of elementary law of friction: dry friction. In Mech. Engrs., paper 7, 1957, pp. 246-251.

[11] F. P. Bowden, D. Tabor, The Friction and Lubrication of Solids, Oxford, Clarendon Press, 1964.

[12] Z. Rymuza, Tribology of polymers, Archives of Civil and Mechanical Eng., 4, 176-184 (2007).

[13] U. S. Tewari, J. Bijwe, Recent Developments in Tribology of Fibre Reinforced Composites with Thermoplastics and Thermosetting Matrices. In: Advances in Composite Tribology, K. Friedrich (Ed.), Elsevier Sci. Publ., 1993, pp. 159-205.

[14] G. M. Gunyaev, Struktura i svojstva polymernyh voloknistyh kompozitov, Khimiya, Moskva, 1981, pp. 200201.

[15] B. Aldousiri, A. Shalwan, C. W. Chin, A review on tribological behaviour of polymeric composites and future reinforcements, Advances in Materials Science and Engineering, vol. 2013, Article ID 645923, http://dx.doi.org/10.1155/2013/645923.

[16] V. Rodriguez, J. Sukumaran, P. De Baets, W. Ost, Y. Perez Delgado, M. Ando, Friction and wear properties of polyamides filled with molybdenum disulphide, $\mathrm{Me}$ chanical Eng. Letters: Research and Development, 5, 68-80 (2011).

[17] J. J. Rajesh, J. Bijwe, U. S. Tewari, Abrasive wear performance of various polyamides, Wear, 252 (9-10) 769 776 (2002).

[18] Nanodiamonds, Advanced Materials Analysis, Properties and Applications. A volume in Micro and Nano Technologies, Chapter 14: Nanodiamonds in composites: polymer chemistry and tribology. Elsevier, 2017, pp. 365-390.

[19] D. L. Burris, B. Boesl, G. R. Bourne, W. G. Sawyer, Polymeric nanocomposites for tribological applications, Macromol. Mater. Eng. 292, 387-402 (2007).

[20] A. M. Hager, M. Davies, in: K. Friedrich (Ed.), Advances in Composite Tribology, Composite Materials Series, vol. 8, Elsevier, Amsterdam, 1993, p. 107.

[21] M. Rubinstein, M. Burdekin, Wear assessment of epoxy composites used for machine slideways, Wear 55 (1), 131-142 (1979).

[22] O. Jacobs, R. Jaskulka, F. Yang, W. Wu, Sliding wear of epoxy compounds against different counterparts under dry and aqueous conditions, Wear 256 (1-2), 9-15 (2004).

[23] Masaki Shimbo, Mitsukazu Ochi, Noritaka Okoyama, Frictional behaviour of cured epoxy resins, Wear 91 (1), 89-101 (1983).

[24] http://www.gallaghrcorp.com/images/kinetc-coefficientgraphs.gif.
[25] Encyklopediya Polimerov, tom 3, Sov.Enciklopediya, Moskva, 1977.

[26] http://www.zeusinc.com/technical white paper-friction and wear of polymers.

[27] H. Unal, A. Mimaroglu, Friction and wear behaviour of unfilled engineering thermoplastics, Material Design 24 183-187 (2003).

[28] K. Watson, K. Talley, J. E. Theberge, Proceedings of the $44^{\text {th }}$ Annual Conference, Composite Institute, The Society of the Plastics Industry, Inc., 1989, Sessions 11-D1 to $11-\mathrm{d} / 9$.

[29] D. M. Nuruzzaman, M. A. Chowdhury, Chapter 14. Friction and wear of Polymer and Composites, INTECH open science, 2012. DOI: http://dx.doi.org/10.5772/48246.

[30] J. S. Anderson, The Wear and Friction of Commercial Polymers and Composites. In K. Friedrich (Ed.), Friction and Wear of Polymer Compositrs, Elsevier Sci. Publ., Amsterdam, 1986, pp. 329-362.

[31] N. Chand, M. Fahrim, Introduction to tribology of polymer composites. In: Tribology of Natural Fiber Polymer Composites, Woodhead Publ. in Composite Sci. \& Technol., 2008, pp. 59-83.

[32] J. K. Lancaster, Proc. Int. Conf. Tribology in the 80's, NASA Conf. Publ. 2300, vol. 1, 1983, Session 1-4, p. 333.

[33] G. Xian, Z. Zhang, Sliding wear of polyetherimide matrix composites. I. Influence of short carbon fiber reinforcement, Wear 258, 776-782 (2005).

[34] J. Khedkar, I. Negulescu, E. I. Meletis, Sliding wear behavior of PTFE composites, Wear 252 (5-6), 361-369 (2002).

[35] J. H. Jia, D. H. Zhou, S. Q. Gao, J. M. Chen, A comparative investigation of the friction and wear behavior of polyimide composites under dry sliding and waterlubricated condition, Materials Sci. Eng. A, 356 (1-2), 48-53 (2003).

[36] B. J. Briscoe, L. H. Yao, T. A. Stolarsik, The Friction and Wear of PTFE/PEEK Composites. In K. C. Ludema (Ed.), Wear of Materials, 1985, ASME, New York, 1985, p. 725.

[37] B. H. Stuart, Tribological studies of poly(ether ether ketone) blends, Tribology International, 31 (11), 647651 (1998).

[38] J. H. Jia, H. D. Zhou, S. Q. Gao, J. M. Chen, A comparative investigation of the friction and wear behavior of polyamide composites under dry sliding and waterlubricated conditions, Materials Science and Engineering, A 356 (1-2), 48-53 (2003).

[39] H. Voss, K. Friedrich, The Wear Behavior of Short Fiber Reinforced Thermoplastics Sliding against Smooth Steel Surfaces. In: K.C. Ludema (Ed), Wear of Materials, 1985, ASME, New York, 1985, p.742.

[40] N. H. Sung, N. P. Suh, Effect of fiber orientation on friction and wear of fiber reinforced polymeric composites, Wear 53, 129-141 (1979).

[41] T. Tzukizoe, N. Ohmae, Friction and Wear Performance of Unidiractionally Glass, Carbon, Aramid and Stainless Fiber-Reinforced Plastics. In: K. Friedrich (Ed), Friction 
and Wear of Polymer Composites, Elsevier Sci. Publ., Amsterdam, 1986, pp. 205-231.

[42] H. M. Hawthorne, Wear in hybrid carbon/glass fiber epoxy composite materials, in K. C. Ludema (Ed), Wear of Materials, 1983, ASME, New York, 1983, p.567.

[43] J. Krey, K. Friedrich, O. Jacobs, Herstellung und Untersuchung der Verschleisseigenschaften von Hochleistungsverbundwekstoffen mit Thermoplastmatrix, VDI-Berichte No. 734, VDI-Verlag, Dusseldorf, 1989, pp.179-194.

[44] P. B. Mody, T. W. Chou, K. Friedrich, Proc. ASTM Symposium on Test Methods and Design Allowables for Fiber Composites, 1989, pp. 75-89.

[45] M. N. Gardos, B. D. MacConnell, Development of HighLoad, High-Temperature Self-Lubricating Composite, Parts I-IV, ASLE-Prepr. 81-3A-3, 81-3A-6, 1981.

[46] K. Friedrich, Wear of Reinforced Polymers by Different Abrasive Counterparts. In: K. Friedrich (Ed), Friction and Wear of Polymer Composites, Elsevier Sci. Publ., Amsterdam, 1986, pp. 233-286.

[47] C. Lhymn, Tribological properties of unidirectional PPS-carbon fiber laminate compositesw, Wear 117, 147-159 (1987).

[48] N. K. Myshkin, I. G. Goryacheva, Tribology: trends in the half-century development, Journal of Friction and Wear 37 (6), 513-516 (2016).
[49] I. G. Goryacheva, M. N. Dobychin, Some results concerning the development of the molecular-mechanical theory of friction, Journal of Friction and Wear, 29 (4) 243-250 (2008).

[50] I. G. Goryacheva, Y. Makhovskaya, Combined effect of surface microgeometry and adhesion in normal and sliding contacts of elastic bodies, Friction 5 (3) 339-350 (2017).

[51] F. M. Borodich, A. Pepelyshev, O. Savencu, Statistical approaches to description of rough engineering surfaces at nano and microscales, Tribology International 103, 197-207 (2016).

[52] A. I. Sviridenok, N. K. Myshkin, I. N. Kovaleva, Latest developments in tribology in the Journal of Friction and Wear, J. Fric. Wear 36 (6), 449-453 (2015).

[53] G. Bogoeva-Gaceva, N. Herakovic, I. Nasov, D. Dimeski, V. Srebrenkoska, V. Stefov, New materials for production of advanced pneumatic and hydraulic valves, Interface 21, August 6-8, Kyoto, Japan 2012.

[54] D. Dimeski, V. Srebrenkoska, G. Bogoeva-Gaceva, V. Stefov, Research report - technology for manufacturing and properties of base composite materials intended for pneumatic valve spools. Eureka project EUREKA E!4548 DE_AMATECH: Development of new actuators, materials and technology for the production of advanced pneumatic and hydraulic valves; April 2010. 
